Check for updates

Cite this: RSC Adv., 2017, 7, 23907

Received 7th March 2017 Accepted 17th April 2017

DOI: 10.1039/c7ra02765f

rsc.li/rsc-advances

\section{Synthesis, characterization and antibacterial evaluation of nanofibrillated cellulose grafted by a novel quinolinium silane salt}

\begin{abstract}
Anita Hassanpour, ${ }^{a}$ Sakineh Asghari (D) *ab and Moslem Mansour Lakouraj ${ }^{a}$
Nanofibrillated cellulose (NFC) is a bio-based nanomaterial with no intrinsic antibacterial properties. In the present study, an NFC derivative with antibacterial properties was prepared by chemical grafting of a novel quinolinium silane salt containing a reactive trimethoxysilane group on the surface of its nanofibrillar network. First, (3-trimethoxysilylpropyl)quinolinium iodide (TMSQI) was synthesized using (3chloropropyl trimethoxysilane) (CPTMS) and quinoline in the presence of potassium iodide. Then, the synthesized TMSQI was covalently grafted on the surface of NFC by a simple adsorption-curing process. The synthesized TMSQI was characterized by ${ }^{1} \mathrm{H}$ and ${ }^{13} \mathrm{C}$ NMR spectroscopies. The grafted NFC samples were also characterized by Fourier transform infrared spectroscopy, elemental analysis, scanning electron microscopy, X-ray diffraction, and thermogravimetric analysis and also tested for antibacterial activity against Gram-positive (S. aureus) and Gram-negative (E. coli) bacteria. The TMSQI-grafted NFC exhibited a successful killing effect against Gram-positive bacteria, whereas bacteriostatic efficiency was found in the grafted NFC samples against Gram-negative bacteria.
\end{abstract}

\section{Introduction}

Over the past few decades, the risk of infectious disease caused by various microorganisms, such as bacteria, has become a major concern to human and environmental health. ${ }^{1}$ Since a number of microbial strains show high levels of resistance to antibiotics and they are evolving much faster than new antibiotics, the treatment of microbial infections can be a difficult task. $^{2}$ In this context, a wide range of antimicrobial materials including polymers and biopolymers, molecular compounds, and nanoparticles have been developed for many applications in the fields ranging from engineering to medicine. ${ }^{3-6}$ In recent years, an ever increasing interest has been focused on the use of green and eco-friendly bio-based materials, especially polysaccharides, because of their inherent renewable character, intrinsic biocompatibility, biodegradability, and nontoxicity towards living organisms. ${ }^{7}$ Among the available natural polysaccharides, cellulose, as one of the most abundant biopolymers, is an excellent candidate for a wide range of applications in various fields including textiles, food packaging, pharmaceuticals, biomedical, and other health-related applications. ${ }^{\mathbf{8 - 1 1}}$

Nanofibrillated cellulose (NFC), as a new generation of nanoscale cellulose material, has unique properties, such as a large specific surface area and high aspect ratio compared to

${ }^{a}$ Department of Chemistry, University of Mazandaran, P. O. Box 47416-95447, Babolsar, Iran. E-mail: s.asghari@umz.ac.ir; Fax: +98 112 5246000; Tel: +98 112 5342350

${ }^{b}$ Nano and Biotechnology Research Group, University of Mazandaran, Babolsar, Iran cellulose fibres. ${ }^{12,13}$ Considering the fact that NFC itself has no antibacterial activity to prevent bacterial infections, ${ }^{\mathbf{1 4}}$ its surface modification with different antibacterial agents via covalent bonding or physical adsorption is of great interest to the development of antibacterial NFC-based biomaterials. ${ }^{15-20}$ However, for the physically adsorbed materials, the potential release of the biocidal agents represents a major drawback that results in a decrease in the antimicrobial effectiveness for longterm applications and adverse effects on the environment and human health due to the residual toxicity of these biocides. Therefore, the creation of permanent antibacterial materials via the covalent grafting of bioactive agents onto the biopolymer surface constitutes an interesting strategy to overcome these problems. Recently, a few reports have been presented for the covalent grafting of antimicrobial agents on the NFC surface. For example, antibacterial NFC-based materials were effectively prepared by the covalent grafting of penicillin, ${ }^{\mathbf{2 1}}$ quaternary ammonium compounds, ${ }^{22-25}$ silanes, ${ }^{26,27}$ anhydrides, ${ }^{28}$ isothiocyanate, ${ }^{29}$ and xanthene dyes. ${ }^{30}$ Among these antibacterial agents, quaternary ammonium compounds are the most widely used class of disinfectants, due to their low toxicity, lack of skin irritation, low corrositivity, good environmental stability and a wide range of antimicrobial activity. ${ }^{31-34}$

These results encouraged us to introduce a novel antibacterial NFC by a simple adsorption-curing process. Herein, a quaternary ammonium group containing trimethoxysilane (TMSQI) was prepared and then grafted onto the surface of NFC. The chemical structure of TMSQI was confirmed from ${ }^{1} \mathrm{H},{ }^{13} \mathrm{C}$ NMR and FT-IR spectroscopies. The morphology and other 
properties of neat and grafted NFC were determined by FT-IR spectroscopy, CHNS elemental analysis, X-ray diffraction (XRD), energy-dispersive X-ray (EDX), field emission scanning electron microscopy (FE-SEM) and thermogravimetric analysis (TGA). The antibacterial activity of TMSQI in aqueous solutions and the grafted NFC were measured both quantitatively and qualitatively against Gram-positive ( $S$. aureus) and Gramnegative (E. coli and $P$. aeruginosa) bacteria.

\section{Experimental}

\section{Materials}

Quinoline, (3-chloropropyl trimethoxysilane) (CPTMS) and potassium iodide (KI) were purchased from Merck Chemical Co. (Darmstadt, Germany) in high purity. All the solvents were purchased from Sigma-Aldrich Chemical Co. (St Louis, MO, USA) and were distilled, purified and dried by standard procedures. Nanofibrillated cellulose (NFC) suspension produced using a disc grinder (MKCA6-2, Masuko Sangyo Co., Ltd., Japan) was kindly provided by Nano Novin Polymer Co. (Sari, Iran) at 3 wt $\%$ consistency.

\section{Instruments}

Fourier transform infrared (FT-IR) spectra of the neat and grafted NFC were taken using a Bruker Tensor 27 spectrometer (Bruker, Karlsruhe, Germany). Vibration bands were reported as the wavenumber $\left(\mathrm{cm}^{-1}\right)$ and the spectra were obtained using the $\mathrm{KBr}$ method. Melting points were determined in open glass capillaries using an Electrothermal IA9100 series digital melting point apparatus (Electrothermal, Essex, UK). ${ }^{1} \mathrm{H}$ and ${ }^{13} \mathrm{C}$ NMR spectra were recorded in $\mathrm{CDCl}_{3}$ solution using a Bruker Avance DRX-400 spectrometer (Bruker, Ettlingen, Germany) at $25^{\circ} \mathrm{C}$. Xray diffraction $(\mathrm{XRD})$ patterns were conducted on a PANalytical X'Pert Pro MPD diffractometer (PANalytical B. V., Almelo, The Netherlands) with $\mathrm{Cu} \mathrm{K} \alpha$ radiation $(\lambda=1.5418 \AA)$ at room temperature. Thermogravimetric analysis (TGA) was carried out on a Netzsch TG 209 F1 analyzer (Netzsch, Selb, Germany) from room temperature to $800{ }^{\circ} \mathrm{C}$ at a heating rate of $10{ }^{\circ} \mathrm{C} \mathrm{min}-1$ under a nitrogen atmosphere. Elemental analyses for $\mathrm{C}, \mathrm{H}$ and $\mathrm{N}$ were performed using a Leco CHNS-932 Analyzer (Leco, St. Joseph, MI, USA). The morphology and the chemical composition of the products were characterized using high-resolution field emission scanning electron microscopy on a MIRA 3XMU (Tescan, Brno, Czech Republic) coupled with energydispersive X-ray analysis (FE-SEM/EDX).

\section{Synthesis of (3-trimethoxysilylpropyl)quinolinium iodide (TMSQI)}

To a three-necked round-bottomed flask equipped with a mechanical stirrer, a nitrogen inlet and reflux condenser, 2.37 $\mathrm{mL}(20 \mathrm{mmol})$ of quinoline and $6.64 \mathrm{~g}(40 \mathrm{mmol})$ of potassium iodide and $60 \mathrm{~mL}$ of dry acetonitrile were introduced. Then, 7.30 $\mathrm{mL}$ (40 mmol) of (3-chloropropyl trimethoxysilane) (CPTMS) was added dropwise to the mixture for $30 \mathrm{~min}$. The reaction mixture was allowed to reflux for $24 \mathrm{~h}$. After completion of the reaction as indicated by TLC (EtOAc/hexane $3: 1$ ), the precipitated potassium chloride was removed by filtration and the solvent was evaporated under reduced pressure. Then, 25 $\mathrm{mL}$ diethyl ether was added to the viscous red-brown residue and the product precipitated as a yellow powder.

Yield: $82 \%$; mp: $128-130{ }^{\circ} \mathrm{C}$; TMSQI ${ }^{1} \mathrm{H}$ NMR $(400.13 \mathrm{MHz}$, $\left.\mathrm{CDCl}_{3}\right): \delta 0.90\left(2 \mathrm{H}, \mathrm{t},{ }^{3} J_{\mathrm{HH}}=8.0 \mathrm{~Hz}, \mathrm{CH}_{2}\right), 2.24\left(2 \mathrm{H}, \mathrm{q},{ }^{3} J_{\mathrm{HH}}=\right.$ $\left.8.0 \mathrm{~Hz}, \mathrm{CH}_{2}\right), 3.58\left(9 \mathrm{H}, \mathrm{s}, 3 \mathrm{OCH}_{3}\right), 5.32\left(2 \mathrm{H}, \mathrm{t},{ }^{3} J_{\mathrm{HH}}=8.0 \mathrm{~Hz}\right.$, $\left.\mathrm{CH}_{2}\right), 7.99\left(1 \mathrm{H}, \mathrm{t},{ }^{3} J_{\mathrm{HH}}=7.6 \mathrm{~Hz}, \mathrm{CH}_{\text {aromatic }}\right), 8.18-8.25(2 \mathrm{H}, \mathrm{m}$, $\left.2 \mathrm{CH}_{\text {aromatic }}\right), 8.40\left(1 \mathrm{H}, \mathrm{d},{ }^{3} \mathrm{JHH}_{\mathrm{HH}}=8.4 \mathrm{~Hz}, \mathrm{CH}_{\text {aromatic }}\right), 8.49(1 \mathrm{H}, \mathrm{d}$, $\left.{ }^{3} J_{\mathrm{HH}}=9.2 \mathrm{~Hz}, \mathrm{CH}_{\text {aromatic }}\right), 9.20\left(1 \mathrm{H}, \mathrm{d},{ }^{3} J_{\mathrm{HH}}=8.4 \mathrm{~Hz}\right.$, $\left.\mathrm{CH}_{\text {aromatic }}\right), 10.27\left(1 \mathrm{H}, \mathrm{d},{ }^{3} \mathrm{~J}_{\mathrm{HH}}=4.8 \mathrm{~Hz}, \mathrm{CH}_{\text {aromatic }}\right)$.

${ }^{13} \mathrm{C}$ NMR (100.6 MHz, $\left.\mathrm{CDCl}_{3}\right): \delta 5.9\left(\mathrm{CH}_{2}-\mathrm{Si}\right), 24.2\left(\mathrm{CH}_{2}\right), 50.9$ $\left(3 \mathrm{OCH}_{3}\right), 59.5\left(\mathrm{CH}_{2}-\mathrm{N}\right), 118.4$ and $122.6(2 \mathrm{CH}), 130.0(\mathrm{Cq})$, $130.3,131.1$ and $136.2(3 \mathrm{CH}), 137.8(\mathrm{Cq}), 147.4$ and $150.0(2 \mathrm{CH})$.

\section{Grafting procedure}

Prehydrolysis of TMSQI. Before reaction with NFC, different amounts of TMSQI $(0.05,0.1,0.25,0.50,1.0,4.0 \mathrm{~g})$ were prehydrolyzed in a mixture of 2-butanol/water $(80: 20 \mathrm{w} / \mathrm{w})$ at a concentration of $10 \%(\mathrm{w} / \mathrm{w})$ for $2 \mathrm{~h}$ at room temperature to form reactive silanol groups.

Grafting of NFC with TMSQI. A drying method was developed that included solvent exchange to alcohol and centrifugation by drying the suspension under subsequent stirring with a glass bar. For that, the NFC aqueous suspension was solvent exchanged from water to 2-butanol by several successive centrifugation at $5000 \mathrm{rpm}\left(15{ }^{\circ} \mathrm{C}\right.$ for $\left.20 \mathrm{~min}\right)$ and redispersion operations. Sonication was performed after each solvent exchange step to avoid aggregation. Then, the suspensions were stirred several times with a glass bar during drying in an oven at $60^{\circ} \mathrm{C}$, until a fine powder of constant weight was obtained. For chemical grafting, NFC $(1 \mathrm{~g})$ in powder form was redispersed in a mixture of 2-butanol/water $(80: 20 \mathrm{w} / \mathrm{w})$ at a nanofibers content of $1.0 \% \mathrm{w} / \mathrm{w}$, then stirred at room temperature for $2 \mathrm{~h}$ and sonicated for $10 \mathrm{~min}$ to get the homogeneous suspension. The grafting was realized by adding the required amount of prehydrolyzed TMSQI $(0.05,0.1,0.25,0.50,1.0,4.0 \mathrm{~g})$ to the resulting NFC suspension and the reaction mixture was stirred at room temperature for $24 \mathrm{~h}$. Afterwards, the suspension of the grafted $\mathrm{NFC}$ was filtered and heated at $110^{\circ} \mathrm{C}$ under vacuum $(5 \mathrm{mmHg})$, for $2 \mathrm{~h}$ in order to promote covalent bonding between the silanol groups of TMSQI and the hydroxyl groups of NFC. Subsequently, the grafted NFC was submitted to a soxhlet extraction with 2butanol for at least $12 \mathrm{~h}$, in order to remove any residual, unbound silane and its condensation products that might not be linked to the nanocellulose surface. Lastly, the grafted NFC powder was dried in a vacuum oven at room temperature.

\section{Antibacterial activity assessment of the TMSQI solution}

In the in vitro biocidal screening, the antibacterial activity of the synthesized TMSQI solution was assessed using the Kirby-Bauer disc diffusion method, in which a filter disc was impregnated with the compound and placed on the surface of an inoculated agar plate. ${ }^{35,36}$ The synthesized compound was dissolved in DMSO to achieve a $20 \mathrm{mg} \mathrm{mL}^{-1}$ solution, then it was sterilised using a $0.22 \mu \mathrm{m}$ Minisart syringe filter (Sartorius). The 
antibacterial activities of the compound were investigated against four bacterial species. The test organisms included Escherichia coli PTCC 1330, Pseudomonas aeruginosa PTCC 1074 and Staphylococcus aureus ATCC 35923. The late exponential phase of the bacteria was prepared by inoculating $1 \%(\mathrm{v} / \mathrm{v})$ of the cultures into the fresh Muller-Hinton broth (Merck) and then incubating on an orbital shaker at $37^{\circ} \mathrm{C}$ and $100 \mathrm{rpm}$ overnight. Before using the cultures, they were standardized with a final cell

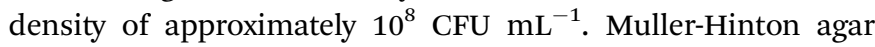
(Merck) was prepared and inoculated from the standardized cultures of the test organisms, then spread as uniformly as possible throughout the entire media. Sterile paper discs $(6 \mathrm{~mm}$ diameter, Padtan, Iran) were impregnated with $20 \mu \mathrm{L}$ of the compound solution. The impregnated disc was introduced on the upper layer of the seeded agar plate and incubated at $37{ }^{\circ} \mathrm{C}$ for $24 \mathrm{~h}$. The antibacterial activity of the synthesized compound was compared to the famous antibiotics gentamicin $(10 \mu \mathrm{g}$ per disc) and chloramphenicol (30 $\mu \mathrm{g}$ per disc) as positive controls. The antibacterial activity was evaluated by measuring the diameter of the inhibition zone ( $\mathrm{mm}$ ) on the surface of the plates and the results were reported as the mean \pm SD after three repeats.

\section{Antibacterial activity of the neat and grafted NFC}

Qualitative assessment of the antibacterial activity. The antibacterial activity of the neat and grafted NFC was analyzed qualitatively by a zone of inhibition test against $S$. aureus (Grampositive) and E. coli and (Gram-negative) bacteria, in order to assess the possibility of TMSQI leakage from the grafted NFC into the environment. The powdered neat and grafted NFC (50 $\mathrm{mg}$ ) materials were prepared in tablet form (diameter: $13 \mathrm{~mm}$, thickness: $1 \mathrm{~mm}$ ) at a pressure of $14 \mathrm{MPa}$, and then were placed on the agar with two different species of bacteria. ${ }^{4}$ In this test, a standardized concentration of bacteria was spread over the surface of a Muller-Hinton agar medium, and the prepared tablets were then placed on the upper layer of the seeded agar surface in plates and incubated at $37^{\circ} \mathrm{C}$ for $24 \mathrm{~h}$. The leaching ability of the grafted NFC was concluded by presence of a zone of inhibition. ${ }^{22}$

Quantitative assessment of the antibacterial activity. The quantitative antibacterial activity of the neat and grafted NFC against $S$. aureus and $E$. coli was evaluated using a dynamic shaking flask method according to the standard ASTM E2149$01 .^{37}$ The bacterial pre-inoculum cultures were grown overnight at $37^{\circ} \mathrm{C}$ in $20 \mathrm{~mL}$ of nutrient broth (made of $1 \mathrm{~g} \mathrm{~L}^{-1}$ beef extract; $5 \mathrm{~g} \mathrm{~L}^{-1}$ neutralized peptone; $2 \mathrm{~g} \mathrm{~L}^{-1}$ yeast extract; $5 \mathrm{~g} \mathrm{~L}^{-1} \mathrm{NaCl}$ ) subjected to horizontal shaking at $100 \mathrm{rpm}$. A typical procedure was as follows: $50 \mathrm{mg}$ of each sample was placed into a $25 \mathrm{~mL}$ flask containing $5 \mathrm{~mL}$ of $5 \%$ nutrient broth in phosphate buffer (0.3 mM, pH 7.2) and inoculated with $1 \times 10^{5} \mathrm{CFU} \mathrm{mL}^{-1}$ bacteria. The samples were incubated for $24 \mathrm{~h}$ at room temperature under vigorous shaking. At 0 and $24 \mathrm{~h}$ contact times, the numbers of colony-forming units (CFU) within the resulting suspensions were calculated using the pour plate method. All the experiments were repeated three times. The bacteria $\log$ reduction of the samples was calculated as follows:

$$
\begin{aligned}
\log \text { reduction }= & \log \mathrm{CFU} T_{24} \text { blank (control) } \\
& -\log \mathrm{CFU} T_{24}(\text { sample })
\end{aligned}
$$

In the standard dynamic shake flask method, at least a 1 log reduction in bacteria load is required to claim antibacterial properties. $^{26,38}$

\section{Results and discussion}

In order to achieve NFC with antibacterial properties, the quaternary ammonium compound (3-trimethoxysilylpropyl) quinolinium iodide (TMSQI) was grafted onto the surface of NFC. Initially, TMSQI was synthesized using (3-chloropropyl trimethoxysilane) (CPTMS) and quinoline in the presence of potassium iodide. The TMSQI compound has a reactive trimethoxysilane moiety as a surface-anchoring group and a positive charge (quaternary quinolinium salt) to confer antibacterial properties. Then, different amounts of TMSQI $(0.05,0.1,0.25$, $0.50,1.0,4.0 \mathrm{~g}$ ) were used for surface covalent grafting of NFC through an adsorption-curing process (Scheme 1). After grafting, the colour of NFC changed from white to yellow. This fact should be ascribed to the addition of TMSQI compound to the NFC.

\section{Characterization of TMSQI}

${ }^{1} \mathrm{H}-\mathrm{NMR}$ and ${ }^{13} \mathrm{C}-\mathrm{NMR}$ spectra of the TMSQI are shown in Fig. 1 and 2, respectively. The aromatic protons of the

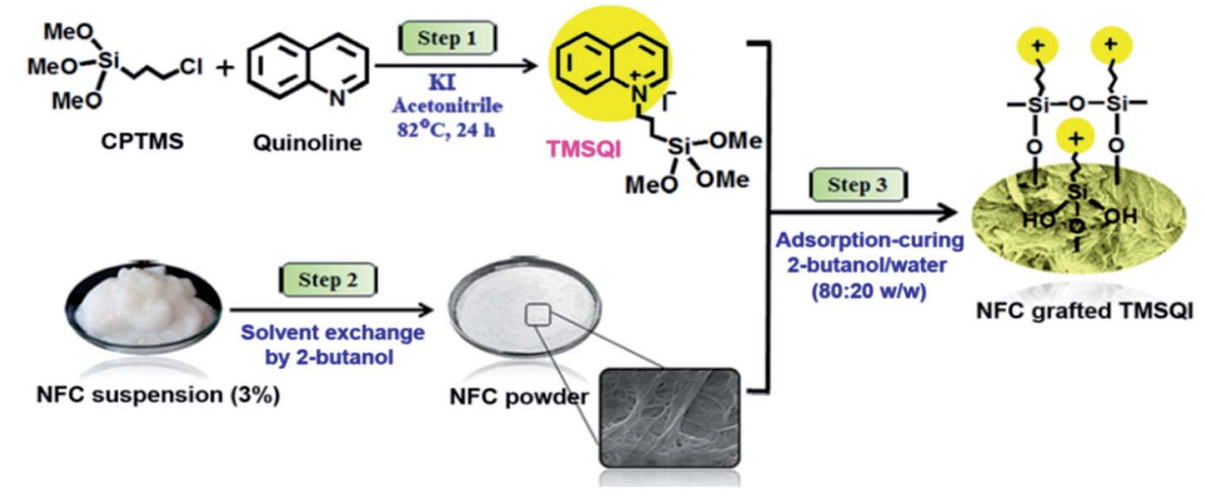

Scheme 1 Schematic of the synthesis of TMSQI and its grafting onto the surface of NFC in 2-butanol/water. 
quinolinium ring appeared as six separate peaks at 7.99, 8.18$8.25,8.40,8.49,9.20$ and 10.27 ppm (e to j). The peak centred at $3.58 \mathrm{ppm}$ should be attributed to $\mathrm{CH}_{3}$ protons of a trimethoxysilane unit, while the methylene protons of the alkyl chain in quinolinium silane salt appeared at 0.90, 2.24 and $5.32 \mathrm{ppm}$.

In the ${ }^{13} \mathrm{C}-\mathrm{NMR}$ spectrum of the synthesized TMSQI (Fig. 2), the carbons of the methylene units of the alkyl chain appeared at 5.9, 24.2 and $50.9 \mathrm{ppm}$ and the methyl carbons of the trimethoxysilane compound resonated at $59.5 \mathrm{ppm}$. The other nine peaks in the range of 118.4-150.0 ppm were related to the carbons of the aromatic rings of quinoline. The NMR results clearly showed that the quinolinium silane salt (TMSQI) had been successfully synthesized.

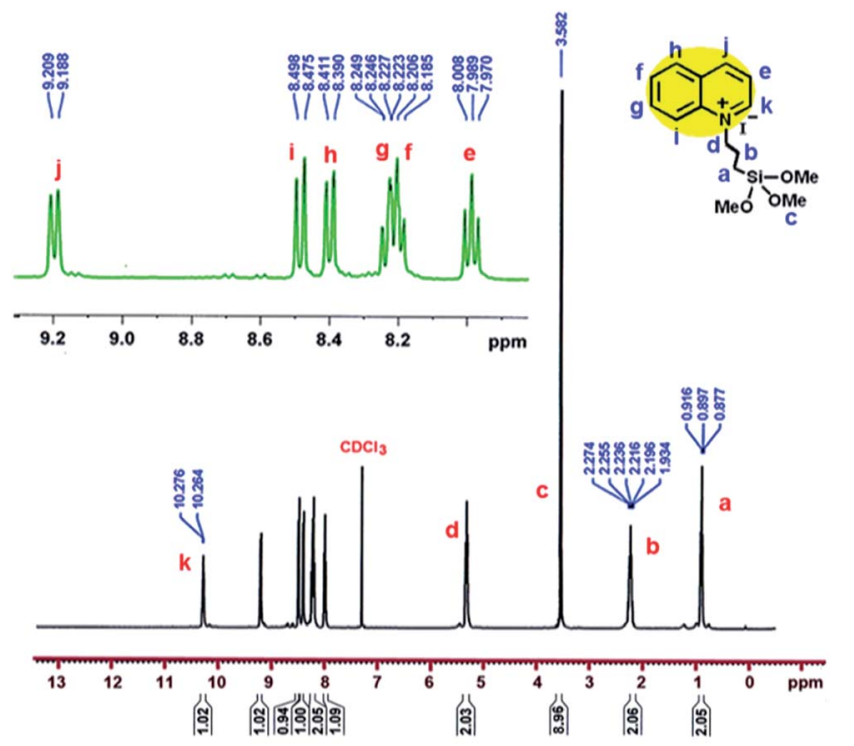

Fig. $1{ }^{1} \mathrm{H}$ NMR spectrum of TMSQI.

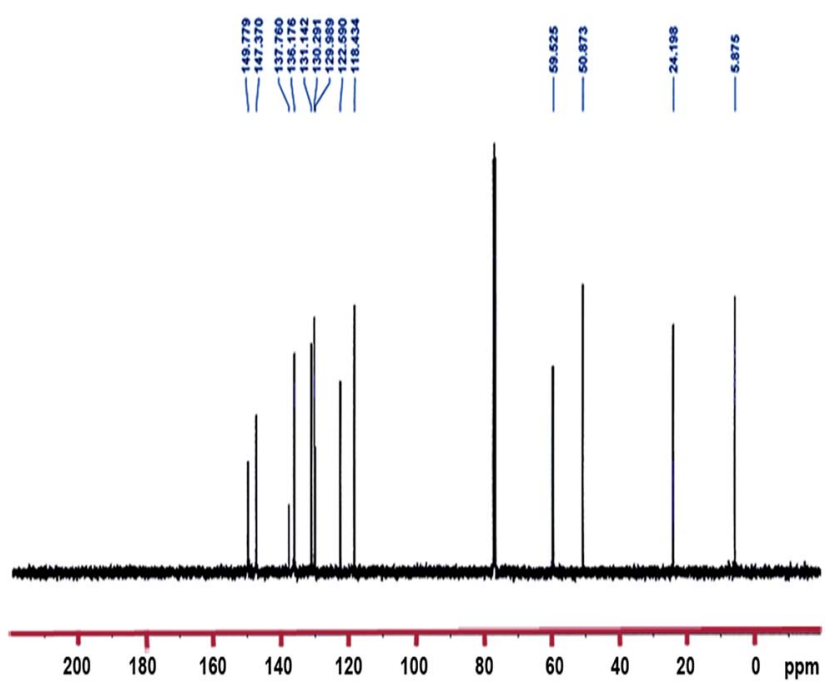

Fig. $2{ }^{13} \mathrm{C}$ NMR spectrum of TMSQI.

\section{Characterization of the grafted NFC with TMSQI}

Infrared spectroscopy is a rapid technique that can be used to determine chemical changes in the grafted cellulosic materials. During grafting, the chemical substitution of $\mathrm{OH}$ groups on the cellulose surface by various amounts of TMSQI was performed in aqueous media. Therefore, the effectiveness of the chemical grafting was characterized by FT-IR spectroscopy to prove any chemical changes in the cellulose structure qualitatively. Fig. 3 compares the FT-IR spectra of TMSQI, neat NFC and NFC 4.0 TMSQI, NFC. The IR spectrum of the synthesized TMSQI (Fig. 3a) showed characteristic absorbance peaks around 3100$3000 \mathrm{~cm}^{-1}$, which were assigned to the aromatic C-H stretching from the quinolinium ring. Three peaks at 1627, 1597 and 1529 $\mathrm{cm}^{-1}$ were ascribed to the stretching vibrations of $\mathrm{C}=\mathrm{N}$ and $\mathrm{C}=\mathrm{C}$ of the quinolinium ring. The vibrations of the $\mathrm{Si}-\mathrm{O}-\mathrm{C}$ bonds appeared at $1079 \mathrm{~cm}^{-1}$ and the peaks at 820 and 776 $\mathrm{cm}^{-1}$ can be attributed to the out-of-plane bending vibrations of the aromatic $\mathrm{C}-\mathrm{H}$ bonds. Neat NFC displayed some characteristic peaks of cellulose: a prominent and broad peak of the $\mathrm{O}-\mathrm{H}$ stretching vibration at around $3416 \mathrm{~cm}^{-1}$, the $\mathrm{C}-\mathrm{H}$ stretching vibration at $2900 \mathrm{~cm}^{-1}$, the $\mathrm{O}-\mathrm{H}$ bending vibration of the adsorbed water at $1646 \mathrm{~cm}^{-1}$, the $\mathrm{CH}_{2}$ bending vibration at 1430 $\mathrm{cm}^{-1}$, the $\mathrm{C}-\mathrm{H}$ bending vibration at $1374 \mathrm{~cm}^{-1}$, the $\mathrm{C}-\mathrm{O}$ stretching vibration at 1115 and $1060 \mathrm{~cm}^{-1}$, the anomeric carbon frequency at $898 \mathrm{~cm}^{-1}$ and the $\mathrm{O}-\mathrm{H}$ out-of-plane bending vibration at $667 \mathrm{~cm}^{-1} \cdot{ }^{39}$ Apart from the typical adsorption bands of cellulose, the FT-IR spectrum of the grafted samples exhibited two new peaks at around 1596 and $1627 \mathrm{~cm}^{-1}$ for $\mathrm{C}=\mathrm{C}$ stretching vibration of the quinolinium ring and $\mathrm{C}=\mathrm{N}$ stretching vibration, respectively. The presence of the $\mathrm{Si}-\mathrm{O}-\mathrm{C}$ and -Si-O-Si- bonds were not easily seen by FT-IR, due to the typical vibrations of these moieties in the range 1000-1200 $\mathrm{cm}^{-1}$ overlapping with the large and intense cellulose $\mathrm{C}-\mathrm{O}-\mathrm{C}$ vibration band..$^{\mathbf{4 0 , 4 1}}$ The peaks at 814 and $773 \mathrm{~cm}^{-1}$ were

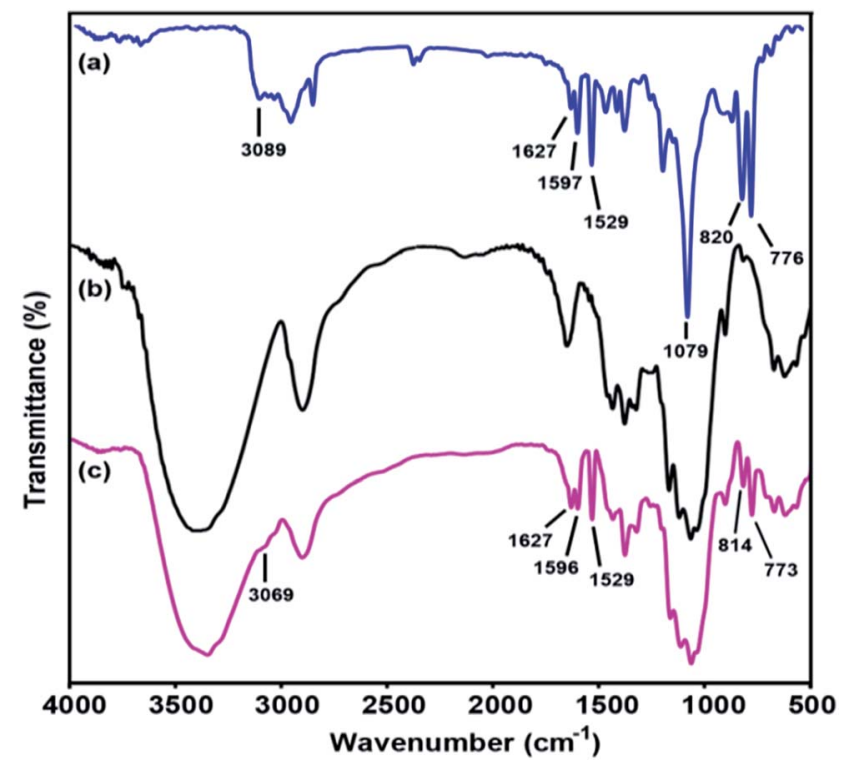

Fig. 3 FT-IR spectra of TMSQI (a), neat NFC (b) and NFC 4.0 TMSQI (c). 
attributed to the out-of-plane bending vibrations of the aromatic - $\mathrm{CH}$ bonds. Furthermore, with an increasing concentration of TMSQI, a very weak peak appeared at about $3069 \mathrm{~cm}^{-1}$, corresponding to the aromatic $-\mathrm{CH}$ stretching from the quinolinium ring. These changes in the characteristic peaks and the presence of new peaks confirmed that TMSQI had been successfully grafted onto the surface of NFC.

\section{Elementary analysis}

In order to investigate the surface composition of the neat and grafted samples, EDX and CHN analysis were performed. EDX analysis (Fig. 4a and b) showed an evolution of the composition between the neat and grafted NFC. The EDX analysis manifested the presence of $\mathrm{C}$ and $\mathrm{O}$ elements without other elements in neat NFC. On the other hand, the EDX spectrum of NFC 4.0 TMSQI showed peaks at 0.39, 1.76 and 3.96 keV corresponding to nitrogen $(\mathrm{N})$, silicon $(\mathrm{Si})$ and iodine (I) respectively, which confirmed the presence of TMSQI on the NFC
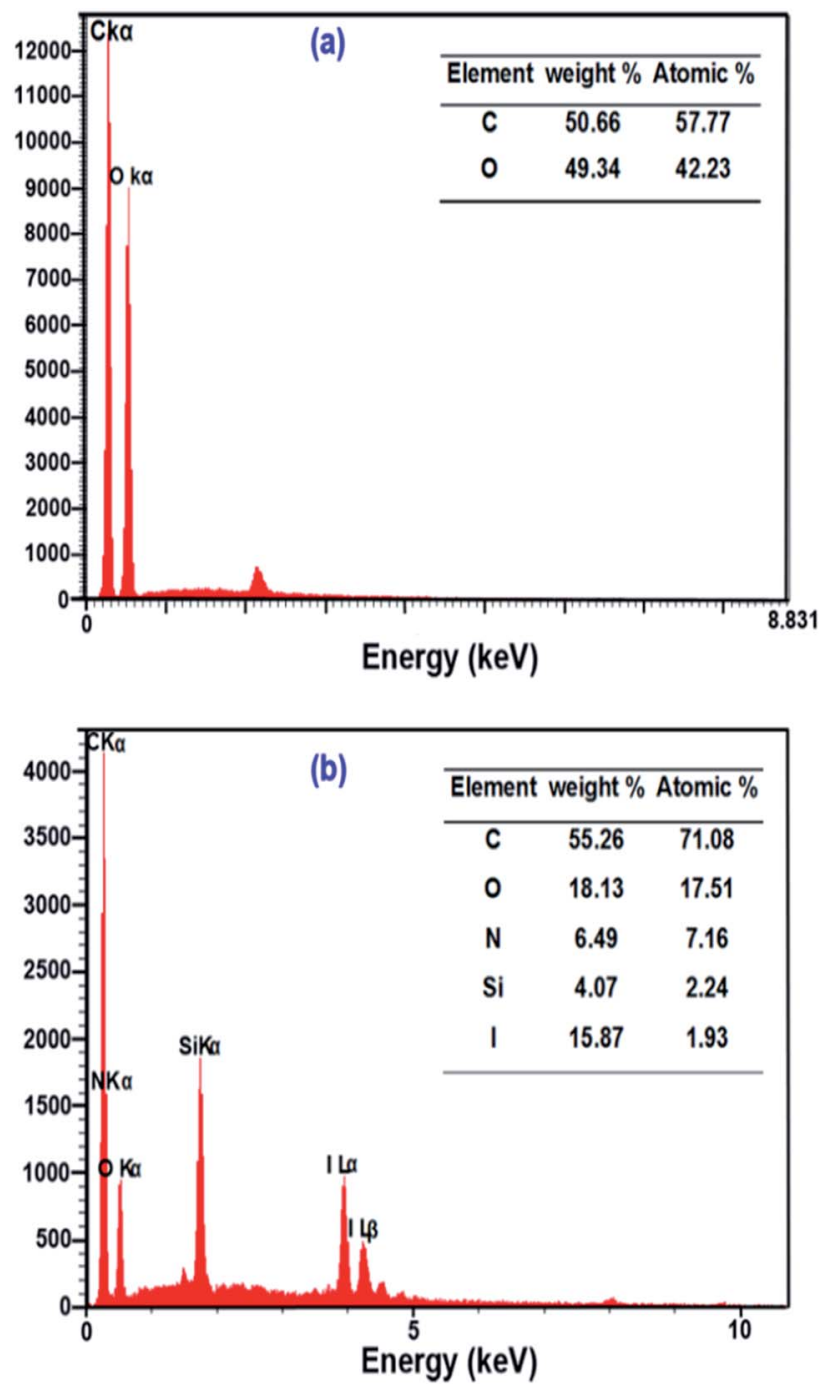

Fig. 4 EDX spectra and tabulated results of neat NFC (a) and NFC 4.0 TMSQI (b). surface. The tabulated results of the quantitative surface analysis are expressed as both the weight percent and atomic percent and showed that the grafted NFC had a considerably higher percentage of carbon compared to neat NFC. The higher level of $\mathrm{C}$ was obtained by chemical grafting of the NFC surface with TMSQI, which provided further evidence about the occurrence of the grafting with TMSQI.

Also, CHN analysis with quantification of each element was performed to further support the EDX results to show that NFC was grafted with TMSQI. The weight percentages of nitrogen, hydrogen and carbon elements in both neat and NFC 4.0 TMSQI were determined using a CHNS analyzer, and the results of the elemental analysis are reported in Table 1. Comparison between the neat and grafted NFC showed the presence of the nitrogen element only in the grafted NFC, thus confirming that grafting of TMSQI on the NFC surface had occurred successfully.

The degree of substitution (DS) of cationic NFC was determined by analyzing the nitrogen content $\left(X_{\mathrm{N}}\right)$ of the grafted sample, according to the following equation: $:^{42,43}$

$$
\mathrm{DS}=\frac{M_{\mathrm{AGU}} \times X_{\mathrm{N}}}{\left(100 \times M_{\mathrm{N}}\right)-\left(M_{\text {groupgrafted }} \times X_{\mathrm{N}}\right)}
$$

where $M_{\mathrm{AGU}}$ is the molecular weight of one anhydroglucose unit $\left(162.14 \mathrm{~g} \mathrm{~mol}^{-1}\right) ; M_{\mathrm{N}}$ is the atomic weight of nitrogen $(14.01 \mathrm{~g}$ $\left.\mathrm{mol}^{-1}\right) ; M_{\text {groupgrafted }}$ is the molecular weight of the TMSQI (419.33 $\mathrm{g} \mathrm{mol}^{-1}$ ) and $X_{\mathrm{N}}$ is the weight percentage of nitrogen in the grafted sample determined by elemental analysis. From the determined nitrogen content (N\%), the DS value of the covalently grafted quinolinium groups of TMSQI on NFC was estimated to be 0.51 .

\section{Morphological study}

In order to study the effects of the covalent grafting of TMSQI on the morphology of the nanofibrils, FE-SEM images of neat NFC and NFC 4.0 TMSQI were taken, as shown in Fig. 5. The FE-SEM micrograph of neat NFC indicated a typical interlaced network structure with filamentary features that overlapped with each other. Also it showed a high density of pores spread over the NFC surface. On the contrary, in the case of the grafted NFC, it seems that although the filamentary shape was preserved, the nanofibrils were thicker and strongly entangled and the overall apparent porosity on the grafted sample decreased. This morphology could be associated with the formation of $\mathrm{Si}-\mathrm{O}-\mathrm{Si}$ bridges on the surface of NFC.

\section{XRD analysis}

$\mathrm{XRD}$ analyses were performed to study the effect of chemical grafting on the crystalline structure of nanocellulose. The XRD patterns of neat NFC and NFC 4.0 TMSQI are presented in

Table 1 CHNS elemental analyses of NFC and NFC 4.0 TMSQI

\begin{tabular}{lllll}
\hline Sample & $\% \mathrm{C}$ & $\% \mathrm{H}$ & $\% \mathrm{~N}$ & $\mathrm{DS}$ \\
\hline NFC & 42.19 & 6.37 & 0 & - \\
NFC 4.0 TMSQI & 41.56 & 5.39 & 1.90 & 0.51
\end{tabular}



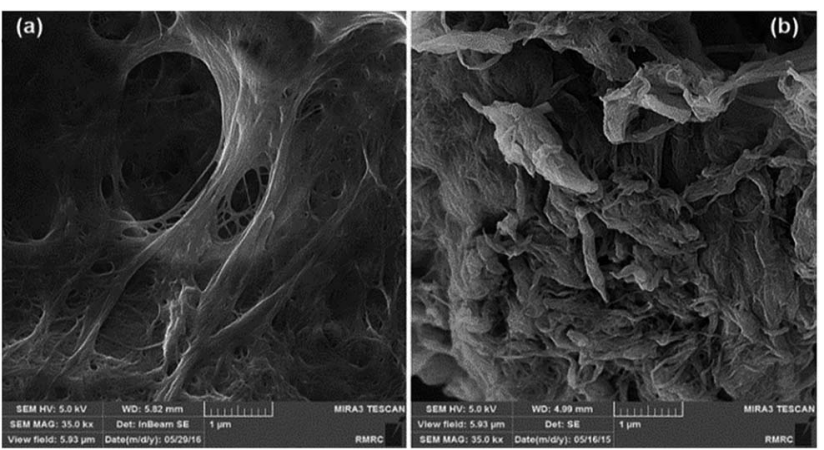

Fig. 5 FE-SEM picture of neat NFC (a) and NFC 4.0 TMSQI (b)

Fig. 6a and b, respectively. In agreement with the other authors, neat NFC showed a typical pattern of cellulose I crystallographic planes ${ }^{44}$ with the most important diffraction peaks at $2 \theta$ values of $14.61^{\circ}, 16.51^{\circ}, 22.65^{\circ}$ and $34.71^{\circ}$, which could be attributed to the diffraction planes of (1-10), (110), (200) and (004), respectively. ${ }^{45,46}$ It is interesting that the typical diffraction peaks of cellulose I were also observed in the XRD pattern of the grafted NFC. This reflects the presence of the crystalline and amorphous structure of the nanocellulose constituent. It seems that the grafting reaction did not disrupt the whole structure of the nanocellulosic matrix. As is evident in Fig. 6b, the peaks intensity in the grafted NFC decreased after the grafting reaction, which indicates a low crystallinity of the grafted NFC relative to the neat NFC. The crystallinity index (CrI, \%) was determined using the empirical method, known as the Segal or peak height method. ${ }^{47,48}$ Based on the XRD analysis, the calculated crystallinity index of the grafted sample decreased to $46 \%$ compared to $61 \%$ for neat NFC. From these results, it can be concluded that the substitution of the hydroxyl groups by the TMSQI compound, which has a greater volume, breaks the intermolecular and intramolecular hydrogen bonds of the

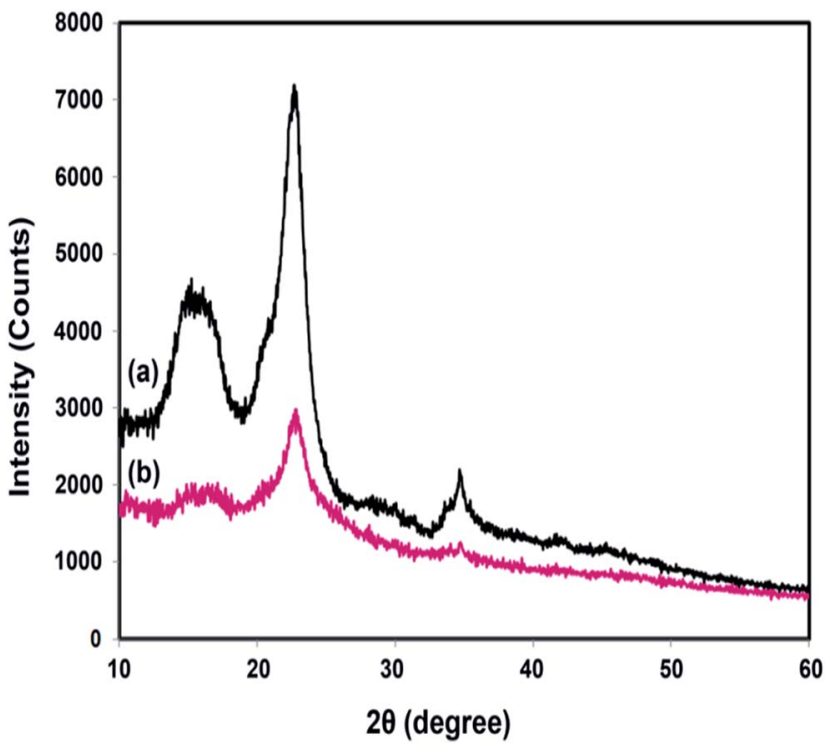

Fig. 6 XRD patterns of neat NFC (a) and NFC 4.0 TMSQI (b). nanocellulose and modifies the crystalline regions of the nanocellulose. Therefore, the crystallinity decreases by the grafting reaction on both the inner and surface hydroxyl groups. ${ }^{49-52}$ Furthermore, the changes in the diffractograms were analyzed in order to determine the crystallite size of the neat and grafted NFC, with the values summarized in Table 2 . Scherrer's equation ${ }^{53}$ was used for estimating the average crystallite size $(D)$ :

$$
D=\frac{K \times \lambda}{\beta \times \cos \theta}
$$

where $K$ is a constant of value $0.9 ; \lambda$ is the wavelength of the $\mathrm{X}$ ray beam $(0.154 \mathrm{~nm}) ; \beta$ is the full width half maxima (FWHM) and $\theta$ is the Bragg angle corresponding to the (200) plane. As can be seen in Table 3, it was observed that the calculated crystallite size of NFC slightly decreased with the grafting of TMSQI, whereas the FWHM of the diffraction peak increased. Thus, neat NFC has more crystalline parts compared to the grafted NFC, which confirms the formation of a disordered structure in the grafted nanofibers.

\section{Thermogravimetric analysis}

The thermal properties of neat NFC and all the grafted samples were determined by thermogravimetry (Fig. 7). According to these TGA curves, the initial weight loss observed in the temperature range of $40-200{ }^{\circ} \mathrm{C}$ could be attributed to evaporation of the physically adsorbed water from the surface. This was about $5.25 \mathrm{wt} \%$ for neat NFC and $4.99-1.71 \mathrm{wt} \%$ for all the TMSQI-grafted NFC samples, which indicates the relatively hydrophobic nature of the grafted NFC samples. The weight loss in the temperature range of $200-390{ }^{\circ} \mathrm{C}$ was $84.74 \%$ for neat NFC, which could be due to the depolymerization of hemicellulose and cleavage of the glycosidic linkages of cellulose..$^{54,55}$ This process is also clearly seen in the DTG graph for neat NFC, which has a monomodal shape with one maximum degradation temperature at $350{ }^{\circ} \mathrm{C}$ (Fig. 7). In addition, the degradation temperature for the grafted samples was found to be $340{ }^{\circ} \mathrm{C}$, $340{ }^{\circ} \mathrm{C}, 290{ }^{\circ} \mathrm{C}, 260{ }^{\circ} \mathrm{C}, 250{ }^{\circ} \mathrm{C}$ and $232{ }^{\circ} \mathrm{C}$ for NFC 0.05 TMSQI, NFC 0.1 TMSQI, NFC 0.25 TMSQI, NFC 0.5 TMSQI, NFC 1.0 TMSQI and NFC 4.0 TMSQI, respectively. These results revealed that the thermal stability of the grafted samples decreased with increasing TMSQI content, since the onset degradation temperature of neat NFC is higher than that of the grafted samples. The grafted sample containing the highest amount of TMSQI ( $4.0 \mathrm{~g})$ showed the lowest initial degradation temperature around $150{ }^{\circ} \mathrm{C}$. This result can be attributed to the presence of a quaternary ammonium salt (TMSQI), which can undergo the Hofmann Elimination in the grafted samples on heating. Furthermore, the earlier onset degradation of the grafted

Table 2 XRD parameters of neat and NFC 4.0 TMSQI

\begin{tabular}{llll}
\hline Sample & $2 \theta(\mathrm{deg})$ & FWHM $(\mathrm{deg})$ & $\begin{array}{l}\text { Crystallite } \\
\text { size }(\mathrm{nm})\end{array}$ \\
\hline Neat NFC & 22.65 & 1.71 & 4.74 \\
NFC 4.0 TMSQI & 22.75 & 1.8 & 4.32
\end{tabular}


Table 3 Antibacterial activity of TMSQI solution

\begin{tabular}{llll}
\hline & \multicolumn{2}{l}{ Zone of growth inhibition $(\mathrm{mm})$} \\
\cline { 2 - 4 } Test strain & TMSQI & $\begin{array}{l}\text { Gentamicin }(10 \\
\mu \text { g per disc })\end{array}$ & $\begin{array}{l}\text { Chloramphenicol } \\
(30 \mu \text { g per disc })\end{array}$ \\
\hline E. coli & $10.5 \pm 0.7$ & $19.6 \pm 1.1$ & $20.7 \pm 1.5$ \\
$P$. aeruginosa & $\mathrm{NE}^{a}$ & $15.6 \pm 0.5$ & $\mathrm{NE}$ \\
S. aureus & $12.0 \pm 1.4$ & $20.3 \pm 1.5$ & $21.7 \pm 0.6$ \\
${ }^{a}$ No effect. & & & \\
& & & \\
\end{tabular}

samples can be attributed to their lower crystallinity compared to neat NFC. ${ }^{52,56,57}$ The crystallinity of NFC decreased after substitution of its hydroxyl groups with TMSQI, which could have a considerable influence on the thermal stability as confirmed by the XRD results. Also, it was interesting to see that the char residue for the grafted samples was higher than that of neat NFC, which was as expected due to the decomposition of the silane linker in the grafted samples. The TGA results showed that the char residue increased by increasing the amount of
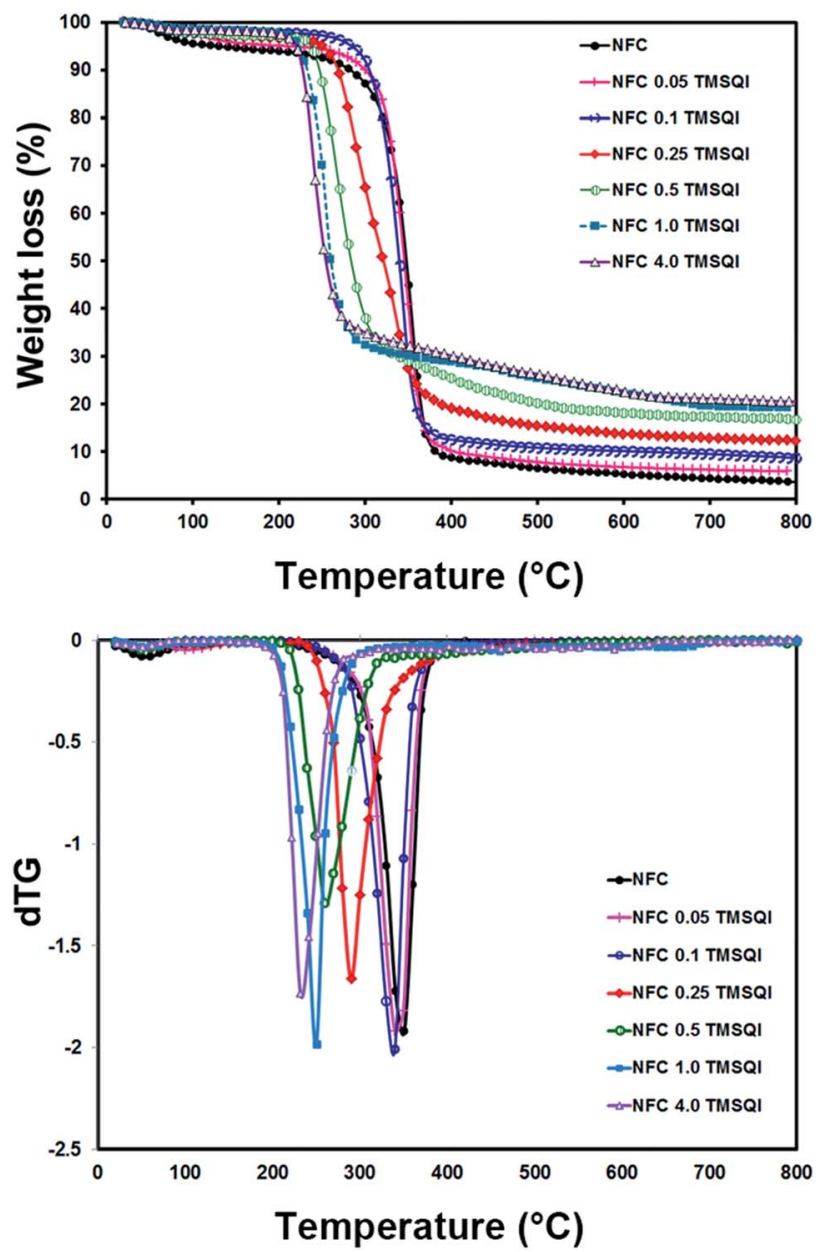

Fig. 7 TGA (a) and DTG (b) of neat NFC and NFC grafted with $0.05-4 \mathrm{~g}$ TMSQI.
TMSQI. When the amount of TMSQI increased from 1.0 to $4.0 \mathrm{~g}$, there was no significant change in the char residue.

\section{Evaluation of the antibacterial activity of TMSQI in solution}

The antimicrobial efficacy of the cationic reactive TMSQI solution was tested against $S$. aureus (Gram-positive) and E. coli and $P$. aeruginosa (Gram-negative) using an agar disc diffusion technique. The results from the inhibition of bacteria were compared with the standard gentamicin and chloramphenicol antibiotics (Table 3). The results revealed that TMSQI was effective against all the tested bacteria except $P$. aeruginosa. The highest zone of inhibition $(12.0 \pm 1.4 \mathrm{~mm})$ was observed against $S$. aureus. The TMSQI compound tends to deteriorate the cell membranes of bacteria, which induces leakage of the intracellular components from bacterial cells; therefore, the inhibition of bacterial growth is effective. Since TMSQI showed antibacterial activity against the selected bacteria in the solution, the study of its antimicrobial activity on NFC substrate was considered to be worthwhile.

\section{Antibacterial activity of grafted NFC}

Qualitative assay of the antimicrobial activity. First, a qualitative assay of the antibacterial activity was performed by the diffusion method ${ }^{22}$ to check the leaching of the antibacterial agent from the grafted NFC. If leaching occurs, it should be possible to observe a clear zone around the grafted sample. Neat NFC was used as a negative reference, which did not show any inhibition zone against all the tested bacterial strains. Also there were no visible zones of inhibition for all the grafted samples, even at the higher final quantity of TMSQI in NFC 4.0 TMSQI (Fig. 8). The results proved that the antibacterial TMSQI was covalently immobilized on the surface of NFC and thus unable to diffuse into the surroundings.

Quantitative assay of the antibacterial activity. The antibacterial activity of the grafted NFC to prevent the growth or even to kill bacteria was quantitatively assessed against Gram-positive (S. aureus) and Gram-negative (E. coli) bacteria. Neat NFC was used as the reference, while as an experiment control the growth of bacteria was tested on flasks only containing inoculated broth media without any samples. There was no reduction in bacterial cells for the culture containing neat NFC; on the contrary, there was at least a $\log$ increase in the values of bacterial growth after $24 \mathrm{~h}$ of incubation for both $S$. aureus and
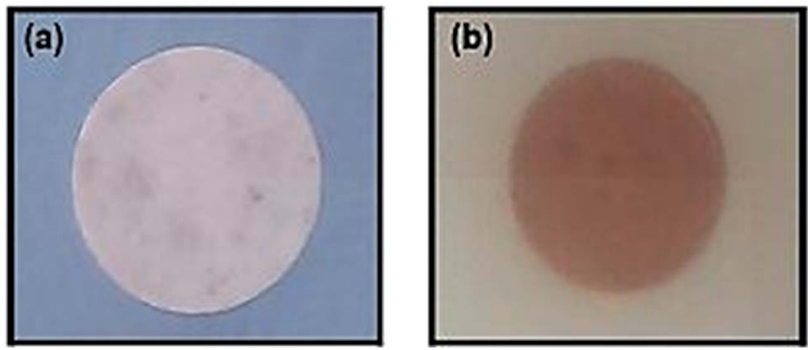

Fig. 8 Zone of inhibition test for neat NFC (a) and NFC 4.0 TMSQI (b) against $S$. aureus. 
E. coli bacterial strains (Fig. 9). In this case, the significant increase in the number of viable bacteria shows that the experiment was done with good nutrient conditions for the proliferation of bacteria. As illustrated in Fig. 8, the TMSQIgrafted NFC samples decreased the bacterial growth and exhibited a partial bactericidal (killing) effect against $S$. aureus after $24 \mathrm{~h}$ of incubation. In general, the antibacterial activity increased gradually with increasing the amount of TMSQI. The samples containing a TMSQI content up to $0.25 \mathrm{~g}$ resulted in a 1-2 log bacterial load reduction with respect to the initial inoculated bacteria, as represented by the line at 5.9. The same protocol was applied to Gram-negative bacteria (E. coli), as shown in Fig. 8. Neat NFC caused the growth of $E$. coli, whereas grafted NFC samples with $0.5,1.0$ and $4.0 \mathrm{~g}$ TMSQI presented complete inhibition of bacterial growth (bacteriostatic effect), where the grafted samples with a lower amount of TMSQI showed a more modest bacteriostatic effect.

It was observed that the antibacterial effect was lower against $E$. coli than $S$. aureus. In the literature, it was noticed that cationic NFC are less active against Gram-negative bacteria. ${ }^{58}$ A typical example is the modification of NFC with 2,3-epoxypropyl trimethylammonium chloride, as reported by Saini et al. (2016), in
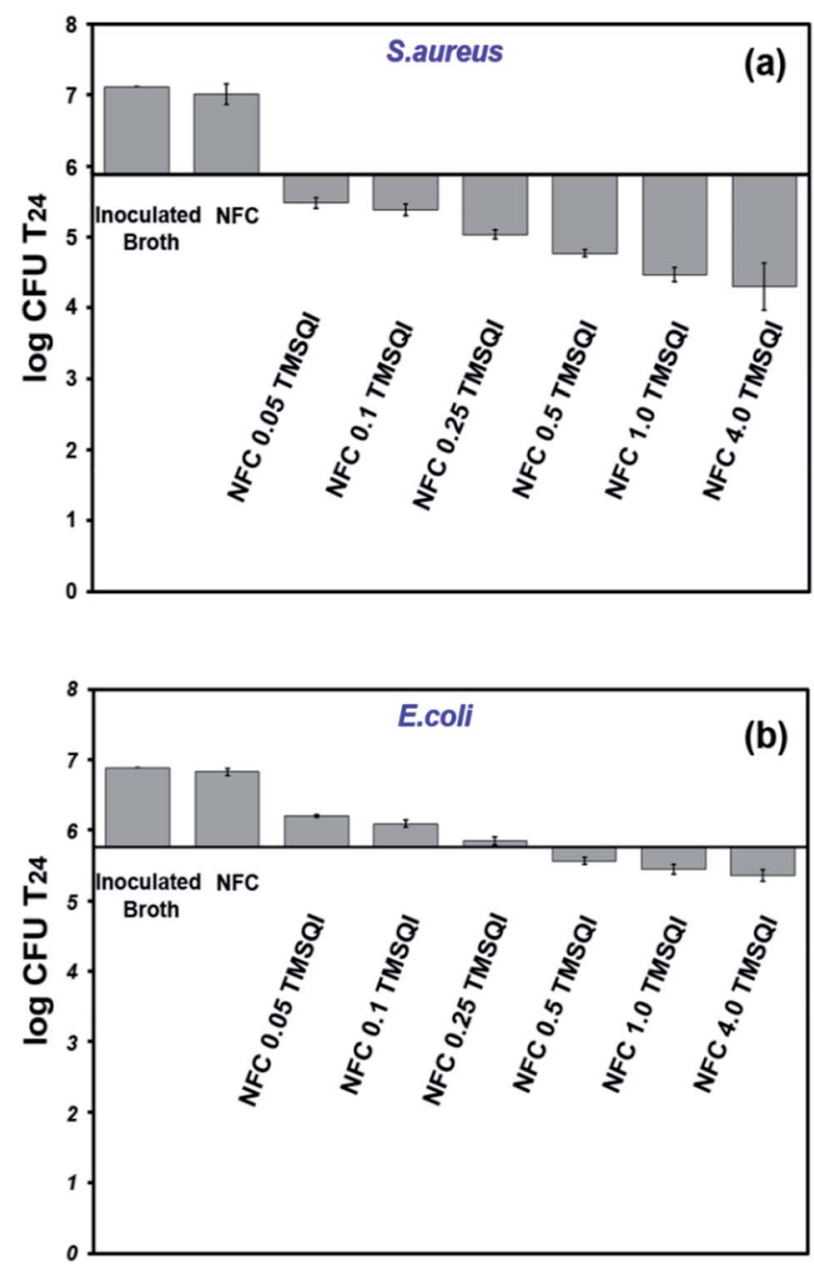

Fig. 9 Antibacterial activity of neat and grafted NFC with different amounts of TMSQI against S. aureus (a) and E. coli (b). which no antibacterial activity was seen with Gram-negative (E. coli) bacteria. ${ }^{23}$ Whereas, the cationic NFC prepared in the present study showed an antibacterial effect against Gram-negative bacteria. Based on our observations, the antibacterial activity seen for the grafted NFC with TMSQI can be directly attributed to the number of quinolinium silane groups on their surface, which increase the cationic nature of the grafted samples with an increasing amount of TMSQI compound. These results are in accordance with the studies done by Fernandes et al. (2013) and Saini et al. (2016) to prepare antimicrobial surfaces by immobilization of aminosilane on the surface of cellulose nanofibers. ${ }^{26,27}$ Furthermore, Andresen et al. (2007), prepared nonleaching antimicrobial surfaces by the covalent grafting of quaternary ammonium silane compounds onto the surface of NFC. ${ }^{22}$ These surfaces also showed a significant reduction in bacterial concentration against both Gram-negative and Gram-positive bacteria, and the antibacterial activity was strongly affected by the amount of the silane concentration present after the grafting. The increased antibacterial activity of the TMSQI-grafted NFC for $S$. aureus can be attributed to the structural differences in the cell wall of Gram-positive bacteria when compared to Gram-negative bacteria. ${ }^{59}$ Although the exact mechanism of the antibacterial action of cationic structures is still unclear, one generally accepted proposal is that the positive charge of TMSQI is expected to interact with the negatively charged bacterial cell membrane by electrostatic interaction and disrupt the membrane integrity, followed by leakage of the intracellular constituents, finally leading to cell death upon contact. ${ }^{\mathbf{6 0}, 61}$ Furthermore, the antibacterial activity of NFC-TMSQI can also be due to the presence of the hydrophobic propyl group, which brings about lipophilic properties to the TMSQI compound and affects the mode of interaction with the cytoplasmic membrane of the bacteria, similar to some previously reported. ${ }^{62}$

\section{Conclusion}

In this study, a new antibacterial bifunctional reactive cationic salt, (3-trimethoxysilylpropyl)quinolinium iodide (TMSQI), was synthesized successfully with a one-step procedure from quinoline and 3-chloropropyl trimethoxysilane (CPTMS), and was then well characterized by ${ }^{1} \mathrm{H}$ and ${ }^{13} \mathrm{C}$ NMR analyses. Antibacterial nanocellulose from dried and redispersed nanofibrillated cellulose (NFC) was also prepared through surface modification of NFC with different amounts of TMSQI. The easier and more accurate determination of the weight of dry NFC powder compared to the conventional aqueous suspensions might provide important advantages. TMSQI was efficiently grafted by covalent bonding onto the surface of NFC, which was confirmed using FT-IR, TGA, XRD and elemental analyses as well as FESEM/EDX analysis. The grafted NFC showed efficient antibacterial activity against both Gram-positive and Gram-negative bacteria at high concentrations of TMSQI in the surface.

\section{Acknowledgements}

The authors would like to acknowledge the University of Mazandaran for financial support of this study. Special thanks 
go to Dr Mojtaba Mohseni, Associated Professor in Microbiology at University of Mazandaran, for assistance in the antibacterial measurements.

\section{References}

1 D. M. Morens, G. K. Folkers and A. S. Fauci, Nature, 2004, 430, 242-249.

2 J. L. Martínez and F. Baquero, Clin. Microbiol. Rev., 2002, 15, 647-679.

3 E. N. Zare, M. M. Lakouraj, M. Mohseni and A. Motahari, Carbohydr. Polym., 2015, 130, 372-380.

4 V. Hasantabar, M. M. Lakouraj, E. N. Zare and M. Mohseni, RSC Adv., 2015, 5, 70186-70196.

5 E.-R. Kenawy, S. Worley and R. Broughton, Biomacromolecules, 2007, 8, 1359-1384.

6 E. Feese, H. Sadeghifar, H. S. Gracz, D. S. Argyropoulos and R. A. Ghiladi, Biomacromolecules, 2011, 12, 3528-3539.

7 M. Rinaudo, Polym. Int., 2008, 57, 397-430.

8 E. M. Fernandes, R. A. Pires, J. F. Mano and R. L. Reis, Prog. Polym. Sci., 2013, 38, 1415-1441.

9 T. S. Anirudhan, J. Nima and P. L. Divya, Appl. Surf. Sci., 2015, 355, 64-73.

10 M. R. De Moura, L. H. Mattoso and V. Zucolotto, J. Food Eng., 2012, 109, 520-524.

11 P. L. Nostro, L. Fratoni and P. Baglioni, J. Inclusion Phenom. Macrocyclic Chem., 2002, 44, 423-427.

12 D. Klemm, F. Kramer, S. Moritz, T. Lindström, M. Ankerfors, D. Gray and A. Dorris, Angew. Chem., Int. Ed., 2011, 50, 54385466.

13 R. J. Moon, A. Martini, J. Nairn, J. Simonsen and J. Youngblood, Chem. Soc. Rev., 2011, 40, 3941-3994.

14 N. Lin and A. Dufresne, Eur. Polym. J., 2014, 59, 302-325.

15 K. Liu, L. Chen, L. Huang, Y. Ni and B. Sun, Carbohydr. Polym., 2015, 117, 996-1001.

16 N. C. Martins, C. S. Freire, R. J. Pinto, S. C. Fernandes, C. P. Neto, A. J. Silvestre, J. Causio, G. Baldi, P. Sadocco and T. Trindade, Cellulose, 2012, 19, 1425-1436.

17 T. Zhang, P. Zhou, Y. Zhan, X. Shi, J. Lin, Y. Du, X. Li and H. Deng, Carbohydr. Polym., 2015, 117, 687-693.

18 S. Saini, C. B. Sillard, M. N. Belgacem and J. Bras, RSC Adv., 2016, 6, 12422-12430.

19 M. Rouabhia, J. r. m. Asselin, N. Tazi, Y. s. Messaddeq, D. Levinson and Z. Zhang, ACS Appl. Mater. Interfaces, 2014, 6, 1439-1446.

20 S. Moritz, C. Wiegand, F. Wesarg, N. Hessler, F. A. Müller, D. Kralisch, U.-C. Hipler and D. Fischer, Int. J. Pharm., 2014, 471, 45-55.

21 S. Saini, N. Belgacem, J. Mendes, G. Elegir and J. Bras, ACS Appl. Mater. Interfaces, 2015, 7, 18076-18085.

22 M. Andresen, P. Stenstad, T. Møretrø, S. Langsrud, K. Syverud, L.-S. Johansson and P. Stenius, Biomacromolecules, 2007, 8, 2149-2155.

23 S. Saini, Ç. Y. Falco, M. N. Belgacem and J. Bras, Carbohydr. Polym., 2016, 135, 239-247.

24 A. Chaker and S. Boufi, Carbohydr. Polym., 2015, 131, 224232.
25 K. Littunen, J. S. de Castro, A. Samoylenko, Q. Xu, S. Quaggin, S. Vainio and J. Seppälä, Eur. Polym. J., 2016, 75, 116-124.

26 S. C. Fernandes, P. Sadocco, A. Alonso-Varona, T. Palomares, A. Eceiza, A. J. Silvestre, I. Mondragon and C. S. Freire, ACS Appl. Mater. Interfaces, 2013, 5, 3290-3297.

27 S. Saini, M. N. Belgacem, M.-C. B. Salon and J. Bras, Cellulose, 2016, 23, 795-810.

28 K. Missoum, P. Sadocco, J. Causio, M. N. Belgacem and J. Bras, Mater. Sci. Eng., C, 2014, 45, 477-483.

29 S. Saini, M. N. Belgacem, K. Missoum and J. Bras, Ind. Crops Prod., 2015, 78, 82-90.

30 H. Hettegger, M. Gorfer, S. Sortino, A. Fraix, D. Bandian, C. Rohrer, W. Harreither, A. Potthast and T. Rosenau, Cellulose, 2015, 22, 3291-3304.

31 D. Roy, J. S. Knapp, J. T. Guthrie and S. Perrier, Biomacromolecules, 2007, 9, 91-99.

32 B. Dizman, M. O. Elasri and L. J. Mathias, J. Polym. Sci., Part A: Polym. Chem., 2006, 44, 5965-5973.

33 J. Meng, X. Zhang, L. Ni, Z. Tang, Y. Zhang, Y. Zhang and W. Zhang, Desalination, 2015, 359, 156-166.

34 W. Z. Xu, G. Gao and J. F. Kadla, Cellulose, 2013, 20, 11871199.

35 L. B. Reller, M. Weinstein, J. H. Jorgensen and M. J. Ferraro, Clin. Infect. Dis., 2009, 49, 1749-1755.

36 F. C. Tenover, J. M. Swenson, C. M. O'Hara and S. A. Stocker, J. Clin. Microbiol., 1995, 33, 1524-1527.

37 O. Yuke, Antimicrofinish, The Antimicrobial Finish Society of Japan Textiles Co, 1989, pp. 182-184.

38 R. J. Pinto, P. A. Marques, C. P. Neto, T. Trindade, S. Daina and P. Sadocco, Acta Biomater., 2009, 5, 2279-2289.

39 J. Lu, P. Askeland and L. T. Drzal, Polymer, 2008, 49, 12851296.

40 S. Saini, M. N. Belgacem, M.-C. B. Salon and J. Bras, Cellulose, 2016, 1-16, DOI: 10.1007/s10570-015-0854-1.

41 L. G. Britcher, D. C. Kehoe, J. G. Matisons and A. G. Swincer, Macromolecules, 1995, 28, 3110-3118.

42 H. de la Motte and G. Westman, Cellulose, 2012, 19, 16771688.

43 F. Zhang, Z. Pang, C. Dong and Z. Liu, Carbohydr. Polym., 2015, 132, 214-220.

44 D. Klemm, B. Heublein, H. P. Fink and A. Bohn, Angew. Chem., Int. Ed., 2005, 44, 3358-3393.

45 J. Miao, Y. Yu, Z. Jiang and L. Zhang, Cellulose, 2016, 23, 1209-1219.

46 A. D. French, Cellulose, 2014, 21, 885-896.

47 L. Segal, J. Creely, A. Martin and C. Conrad, Text. Res. J., 1959, 29, 786-794.

48 T. Ho, T. Zimmermann, R. Hauert and W. Caseri, Cellulose, 2011, 18, 1391-1406.

49 W. Hu, S. Chen, Q. Xu and H. Wang, Carbohydr. Polym., 2011, 83, 1575-1581.

50 H. Du, C. Liu, X. Mu, W. Gong, D. Lv, Y. Hong, C. Si and B. Li, Cellulose, 2016, 1-19, DOI: 10.1007/s10570-016-0963-5.

51 M. S. Khalil-Abad, M. E. Yazdanshenas and M. R. Nateghi, Cellulose, 2009, 16, 1147-1157. 
52 Z.-T. Liu, Y. Yang, L. Zhang, Z.-W. Liu and H. Xiong, Cellulose, 2007, 14, 337-345.

53 F. Lionetto, R. Del Sole, D. Cannoletta, G. Vasapollo and A. Maffezzoli, Materials, 2012, 5, 1910-1922.

54 A. G. Bradbury, Y. Sakai and F. Shafizadeh, J. Appl. Polym. Sci., 1979, 23, 3271-3280.

55 M. J. J. Antal and G. Varhegyi, Ind. Eng. Chem. Res., 1995, 34, 703-717.

56 J. Zhu, J. Brighton, H. Zhu and H. Abhyankar, Journal of Scientific Research and Reports, 2014, 4, 1-11.

57 C. Yin, J. Li, Q. Xu, Q. Peng, Y. Liu and X. Shen, Carbohydr. Polym., 2007, 67, 147-154.
58 L. Sun, Y. Du, L. Fan, X. Chen and J. Yang, Polymer, 2006, 47, 1796-1804.

59 T. J. Silhavy, D. Kahne and S. Walker, Cold Spring Harbor Perspect. Biol., 2010, 2, a000414.

60 H. Murata, R. R. Koepsel, K. Matyjaszewski and A. J. Russell, Biomaterials, 2007, 28, 4870-4879.

61 M. Kong, X. G. Chen, K. Xing and H. J. Park, Int. J. Food Microbiol., 2010, 144, 51-63.

62 J.-W. Rhim, S.-I. Hong, H.-M. Park and P. K. Ng, J. Agric. Food Chem., 2006, 54, 5814-5822. 